\title{
A numerical taxonomic study of the gram-positive anaerobic cocci
}

\author{
D. A. MURDOCH and J. T. MAGEE*
}

Department of Microbiology, Southmead Hospital, Bristol BS10 5NB and - Department of Medical Microbiology and Public Health Laboratory, University Hospital of Wales, Heath Park, Cardiff CF4 4XW

\begin{abstract}
Summary. Clinical (101) and collection (26) strains of gram-positive anaerobic cocci were examined in conventional tests and pyrolysis mass spectrometry (PMS). Numerical classifications based upon conventional test reaction patterns (CTRPs) and PMS showed 27 and 22 clusters, respectively. Cross-tabulation of cluster membership in the two classifications showed excellent correlation, with the combined classifications showing clear groups corresponding to the currently recognised species Peptostreptococcus anaerobius, $P$. heliotrinreducens, $P$. hydrogenalis, $P$. indolicus, $P$. lactolyticus, $P$. magnus, $P$. micros and Peptococcus niger. Strains of $P$. prevotii and $P$. tetradius clustered together in a heterogeneous group of saccharolytic organisms. However, strains previously identified as $P$. asaccharolyticus were divided into three distinct groups in PMS, two of which differed only in indoleassociated pyrolysis products. A further four groups and several single-member clusters were distinct from these species. PMS data supported the validity of identification by pre-formed enzyme profiles and confirmed that Hare group III is synonymous with $P$. hydrogenalis, Hare group IV with $P$. magnus, and the "ADH group" with $P$. vaginalis. There is clearly a need for a taxonomic revision of the genus Peptostreptococcus, which probably encompasses several generic groups.
\end{abstract}

\section{Introduction}

Gram-positive anaerobic cocci (GPAC) are found as commensal flora of all skin and mucosal surfaces ${ }^{1-4}$ and are commonly isolated from human infections. ${ }^{5-8}$ They have been little studied because of difficulties in culture and identification; most GPAC are asaccharolytic. ${ }^{2.9 .10}$ yielding largely negative results in traditional biochemical tests. ${ }^{4.10 .11}$ Improvements in anaerobic culture and the introduction of pre-formed enzyme tests ${ }^{9.12-14}$ have resolved these technical problems. However. several recent studies ${ }^{14-17}$ indicate that the classification of the GPAC could be improved.

One of these studies ${ }^{14}$ reported identification results for a large collection of clinical and reference strains of GPAC. Here, we report a further classification study of this collection in two sets of phenotypic tests: conventional test reaction patterns (CTRPs), which reflect the metabolic interactions of the organism with its environment. and pyrolysis mass spectrometry (PMS). which reflects overall cell composition. ${ }^{18}$ The assumption was that a classification based on this broad range of characters should be highly predictive of the underlying genotypic structure of the group, providing a basis for future studies with slower, lowthroughput, genotypic methods. Furthermore, these methods allowed examination of many isolates, increasing the probability that rare taxa would be revealed. The combination has proved a powerful tool in taxonomic studies of the corynebacteria, ${ }^{19}$ fusobacteria ${ }^{20}$ and the "Streptococcus milleri" group. ${ }^{21}$ The aims were to document deficiencies in the current classification and to compare the results with earlier pre-formed enzyme profile (PEP) work on the identification of GPAC. ${ }^{14}$

\section{Materials and methods}

\section{Bacterial strains}

Collection (26) and clinical (101) strains were examined (tables I and II). Of the clinical strains, 90 were selected from a previously described ${ }^{14}$ collection from St Bartholomew's Hospital, London, to represent the full range from typical to highly atypical strains. These were supplemented with 11 strains 
isolated at Southmead Hospital, Bristol—-seven strains resembling Peptostreptococcus tetradius, one resembling $P$. indolicus and three resembling $P$. hydrogenalis. Collection strains were acquired recently from the appropriate reference collections and included the type strains of Peptococcus niger and all recognised species in the genus Peptostreptococcus. Storage and culture were as described previously. ${ }^{14}$

\section{Characterisation in conventional tests}

Detailed methods were reported previously. ${ }^{14} \mathrm{Col}-$ onial characters were scored as 1 (positive) or 0 (negative) for the following: colony size $>1 \mathrm{~mm}$ after incubation for $48 \mathrm{~h}$; colony size $\geqslant 2 \mathrm{~mm}$ after incubation for 5 days; each of the four colony colours (white, pink, grey, yellow) noted after incubation for 5 days; and each of the three colony odours noted (unpleasant, plasticine-like, musty). Microscopic characters were scored as: cell size (large, 4 ; medium, 3 ; small, 2; tiny, 1); variation in cell size (difference between the cell size scores for largest and smallest cells commonly found); and presence (1) or absence (0) of tetrads, chains and diplococci. Production of the volatile fatty acids (VFAs) acetic, propionic, $n$ - and iso-butyric, $n$ - and iso-valeric, and $n$ - and iso-caproic were coded 0,1 or 2 (absent, weak positive or strong positive). Susceptibilities (sensitive, 0 ; intermediate, 1 ; resistant, 2) to metronidazole, vancomycin, novobiocin and sodium polyethanol sulphonate (SPS) were determined by the disk diffusion method as described previously. ${ }^{14}$ Susceptibilities to two further antibiotics, polymixin B (10- $\mu \mathrm{g}$ disk) and neomycin (30- $\mu \mathrm{g}$ disk) were tested by the same method and recorded as zone size $>15 \mathrm{~mm}$, sensitive and zone size $<12 \mathrm{~mm}$, resistant. PEPs were determined for the 29 substrates of the ATB 32A kit (API bioMérieux, Basingstoke, Hants), ${ }^{14}$ and scored 0 (negative), 1 (weak positive), 2 (moderate positive) or 3 (strong positive). Catalase production was scored as 0 (negative) or 1 (positive). In all, 13 bi-state and 45 multi-state characters were recorded.

\section{Pyrolysis mass spectrometry}

Strains were grown on enriched blood agar (ERB; Columbia Agar Base, Difco, with horse blood 6\%, haemin $5 \mathrm{mg} / \mathrm{L}$ and menadione $1 \mathrm{mg} / \mathrm{L}$ to enhance growth) and subcultured on to ERB with an additional $0.2 \%$ Agar No. 2 (Oxoid) to increase the gel strength. All plates were from the same batch of medium. The strains were each assigned a randomised blind code, and 12 strains, chosen at random, were assigned two independent codes as blind duplicate controls. Three or four plates were inoculated for each blind code and incubated at $37^{\circ} \mathrm{C}$ for $48 \mathrm{~h}$ in an anaerobic cabinet (Microflow Anaerobic Systems, M.D.H.) in an atmosphere of $\mathrm{H}_{2} 10 \%, \mathrm{CO}_{2} 10 \%, \mathrm{~N}_{2} 80 \%$. Colony material from each coded culture set was smeared on to pyrolysis foils, sampling either two or four plates to prepare quadruplicate foils, according to the density of growth. Foils were heated at $80^{\circ} \mathrm{C}$ for $10 \mathrm{~min}$ within $10 \mathrm{~min}$ of sampling and stored in a vacuum desiccator for $48 \mathrm{~h}$. The foils were analysed in a PYMS 200X automated pyrolysis mass spectrometer (Horizon Instruments, Heathfield, Sussex), pyrolysing at $530^{\circ} \mathrm{C}$ for $4 \mathrm{~s}$, and collecting data for pyrolysis products with mass:charge $(\mathrm{m}: \mathrm{z})$ ratios 50-150. The PMS apparatus, principles and methods have been described previously. ${ }^{18-21}$

\section{Classification analysis}

This was performed as previously ${ }_{19}^{19}$ but the analysis has been transferred to a 486DX PC computer, with Turbo Basic programs to normalise the PMS data, transfer it to the SPSS-PC program suite and then to Clustan-PC version 2. Preliminary processing of normalised ${ }^{18,19}$ PMS spectra in discriminant analysis reduced inter-strain spectrum differences to squared Euclidian statistical distances, which were regarded as a measure of strain dissimilarity. ${ }^{18}$

Classification analyses were programmed in Clustan-PC with the UPGMA clustering strategy. Classifications obtained with five similarity coefficients were examined: squared Euclidean distance (SED); size coefficient; cosine function; shape function; and correlation coefficient. ${ }^{22}$ This range of coefficients permits a range of emphasis, weighting either the quantitative or the qualitative aspects of inter-strain differences, and allows inspection of different aspects of the data. For PMS data, the Normix strategy ${ }^{19,22}$ was used to examine the resulting dendrograms for an optimal cut-off delineating group structure. As Normix is limited to analysis of continuous variables, the cluster distance delineating groups in the CTRP classification was judged subjectively.

\section{Identification analyses}

The teaching-challenge set strategy described previously $^{19}$ was used to test the homogeneity within and discrimination between groups. Only groups with more than five members were tested, to avoid the inherent difficulties of identification from small teaching sets. ${ }^{19}$

\section{Results}

\section{Classification analyses}

Cluster membership of the strains (tables I and II) varied little between the various classification strategies, indicating consistency of the quantitative and qualitative aspects of within-group variation. In PMS, the blind replicate controls invariably clustered as close neighbours. The CTRP and PMS classifications based on the SED coefficient are illustrated in 
Table I. Cluster membership of major groups

\begin{tabular}{|c|c|c|c|c|c|}
\hline \multirow{2}{*}{$\begin{array}{l}\text { Group } \\
\text { designation }\end{array}$} & \multirow{2}{*}{$\begin{array}{l}\text { Collection strains } \\
\text { within group }\end{array}$} & \multicolumn{2}{|c|}{$\begin{array}{l}\text { Number of } \\
\text { strains }\end{array}$} & \multicolumn{2}{|c|}{$\begin{array}{l}\text { Cluster } \\
\text { in }\end{array}$} \\
\hline & & Clinical & Total & CTRPs & PMS \\
\hline $\begin{array}{l}\text { P. magnus } \\
\text { + Hare Group IV* }\end{array}$ & $\begin{array}{l}\text { N11804, A14956, } \\
\text { D20369, N9804*, } \\
\text { N9815* }\end{array}$ & 10 & 15 & A & 3 \\
\hline "P. asaccharolyticus A" & $\begin{array}{l}\text { N11461 } \\
\text { D20364 }\end{array}$ & $\begin{array}{r}0 \\
10 \\
0\end{array}$ & $\begin{array}{r}1 \\
10 \\
1\end{array}$ & $\begin{array}{l}\mathrm{C} \\
\mathrm{C} \\
\mathrm{F}\end{array}$ & $\begin{array}{r}21 \\
1 \\
1\end{array}$ \\
\hline$" P$. asaccharolyticus B" & & $\begin{array}{l}1 \\
4 \\
3 \\
1\end{array}$ & $\begin{array}{l}1 \\
4 \\
3 \\
1\end{array}$ & $\begin{array}{l}C \\
D \\
E \\
F\end{array}$ & $\begin{array}{l}18 \\
18 \\
18 \\
18\end{array}$ \\
\hline$" P$ asaccharolyticus I" & & 4 & 4 & $\mathrm{E}$ & 12 \\
\hline $\begin{array}{l}\text { P. indolicus } \\
P . \text { indolicus? }\end{array}$ & $\underline{\mathrm{N} 11088}$ & $\begin{array}{l}0 \\
2\end{array}$ & $\begin{array}{l}1 \\
2\end{array}$ & $\begin{array}{l}\mathrm{G} \\
\mathrm{G}\end{array}$ & $\begin{array}{l}20 \\
13\end{array}$ \\
\hline $\begin{array}{l}\text { P. hydrogenalis } \\
+ \text { Hare Group III* }\end{array}$ & $\frac{\mathrm{D} 7454,}{\mathrm{~N}^{2} 14^{*}}$ & 6 & 9 & $\mathrm{H}$ & 11 \\
\hline "trisimilis" group & & 3 & 3 & I & 8 \\
\hline$P$. vaginalis & $\underline{D} 7457$ & $\begin{array}{l}4 \\
3 \\
1 \\
1\end{array}$ & $\begin{array}{l}5 \\
3 \\
1 \\
1\end{array}$ & $\begin{array}{l}\mathrm{J} \\
\mathrm{J} \\
\mathrm{J} \\
\mathrm{K}\end{array}$ & $\begin{array}{r}6 \\
16 \\
24 \\
10\end{array}$ \\
\hline "bGAL" group & & $\begin{array}{l}6 \\
1 \\
2\end{array}$ & $\begin{array}{l}6 \\
1 \\
2\end{array}$ & $\begin{array}{l}\mathrm{L} \\
\mathrm{L} \\
\mathrm{L}\end{array}$ & $\begin{array}{r}5 \\
6 \\
10\end{array}$ \\
\hline Hare Group VIII & N9820, N9810 & 2 & 4 & $\mathrm{~N}$ & 9 \\
\hline "ivoricus" group & & $\begin{array}{l}3 \\
1\end{array}$ & $\begin{array}{l}3 \\
1\end{array}$ & $\begin{array}{l}\mathrm{O} \\
\mathrm{O}\end{array}$ & $\begin{array}{l}22 \\
23\end{array}$ \\
\hline P. anaerobius & $\underline{N 11460}$ & $\begin{array}{l}1 \\
2 \\
4\end{array}$ & $\begin{array}{l}1 \\
2 \\
5\end{array}$ & $\begin{array}{l}\mathrm{Q} \\
\mathrm{R} \\
\mathrm{R}\end{array}$ & $\begin{array}{l}26 \\
22 \\
25\end{array}$ \\
\hline P. prevotii/tetradius & 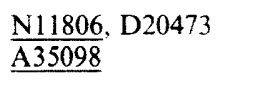 & $\begin{array}{l}7 \\
0 \\
3\end{array}$ & $\begin{array}{l}9 \\
1 \\
3\end{array}$ & $\begin{array}{l}\mathrm{S} \\
\mathrm{S} \\
\mathrm{S}\end{array}$ & $\begin{array}{l}4 \\
7 \\
5\end{array}$ \\
\hline P. heliotrinreducens & & 5 & 5 & $\mathrm{~T}$ & 27 \\
\hline $\begin{array}{l}\text { P. micros } \\
+ \text { Hare Group } \mathrm{IXb}^{*}\end{array}$ & $\begin{array}{l}\text { N11808 } \\
\text { N9821* }\end{array}$ & $\begin{array}{l}1 \\
6 \\
1 \\
2\end{array}$ & $\begin{array}{l}2 \\
6 \\
1 \\
3\end{array}$ & $\begin{array}{l}\text { U } \\
\text { V } \\
\text { V } \\
\text { V }\end{array}$ & $\begin{array}{r}2 \\
2 \\
17 \\
15\end{array}$ \\
\hline
\end{tabular}

N. NCTC: A, ATCC: D, DSM; underlined collection numbers indicate type strains. ${ }^{*}$ Designations of collection strains.

Table II. Cluster membership of minor groups

\begin{tabular}{|c|c|c|c|c|c|}
\hline \multirow{2}{*}{$\begin{array}{l}\text { Group } \\
\text { designation }\end{array}$} & \multirow{2}{*}{$\begin{array}{l}\text { Collection } \\
\text { strains } \\
\text { within } \\
\text { group }\end{array}$} & \multicolumn{2}{|c|}{$\begin{array}{l}\text { Number of } \\
\text { strains }\end{array}$} & \multicolumn{2}{|c|}{$\begin{array}{l}\text { Cluster } \\
\text { in }\end{array}$} \\
\hline & & Clinical & Total & CTRPs & PMS \\
\hline Hare Group IXb & N9811 & 0 & 1 & $A$ ? & 12 \\
\hline Hare Group VIIa & N9808 & 0 & 1 & B & 14 \\
\hline P. barnesae & D3244 & 0 & 1 & C? & 3 \\
\hline Hare Group I & $\overline{\mathrm{N} 9801}$ & 0 & 1 & C? & 11 \\
\hline P. lacrimalis & D7455 & 0 & 1 & $\mathrm{D}$ ? & 12 \\
\hline P. lactolsticus & $\bar{D} 7456$ & 0 & $i$ & $\mathbf{M}$ & 10 \\
\hline$P c$ niger & $\mathrm{N11805}$ & 0 & 1 & $\mathbf{P}$ & 19 \\
\hline
\end{tabular}

N, NCTC; D, DSM; underlined designations indicate type strains. ? indicates that the strain was an outlier of the cluster.

figs. 1 and 2. For this coefficient, Normix showed an optimal group structure at the 27 cluster level. For the three other similarity coefficients, this optimum was found at the 27,26 and 28 group levels. The correlation between CTRP and PMS classifications is shown in tables I and II; most of the disagreements involved subdivision of a single CTRP group into several PMS groups, as in previous taxonomic surveys. ${ }^{19,21}$ 


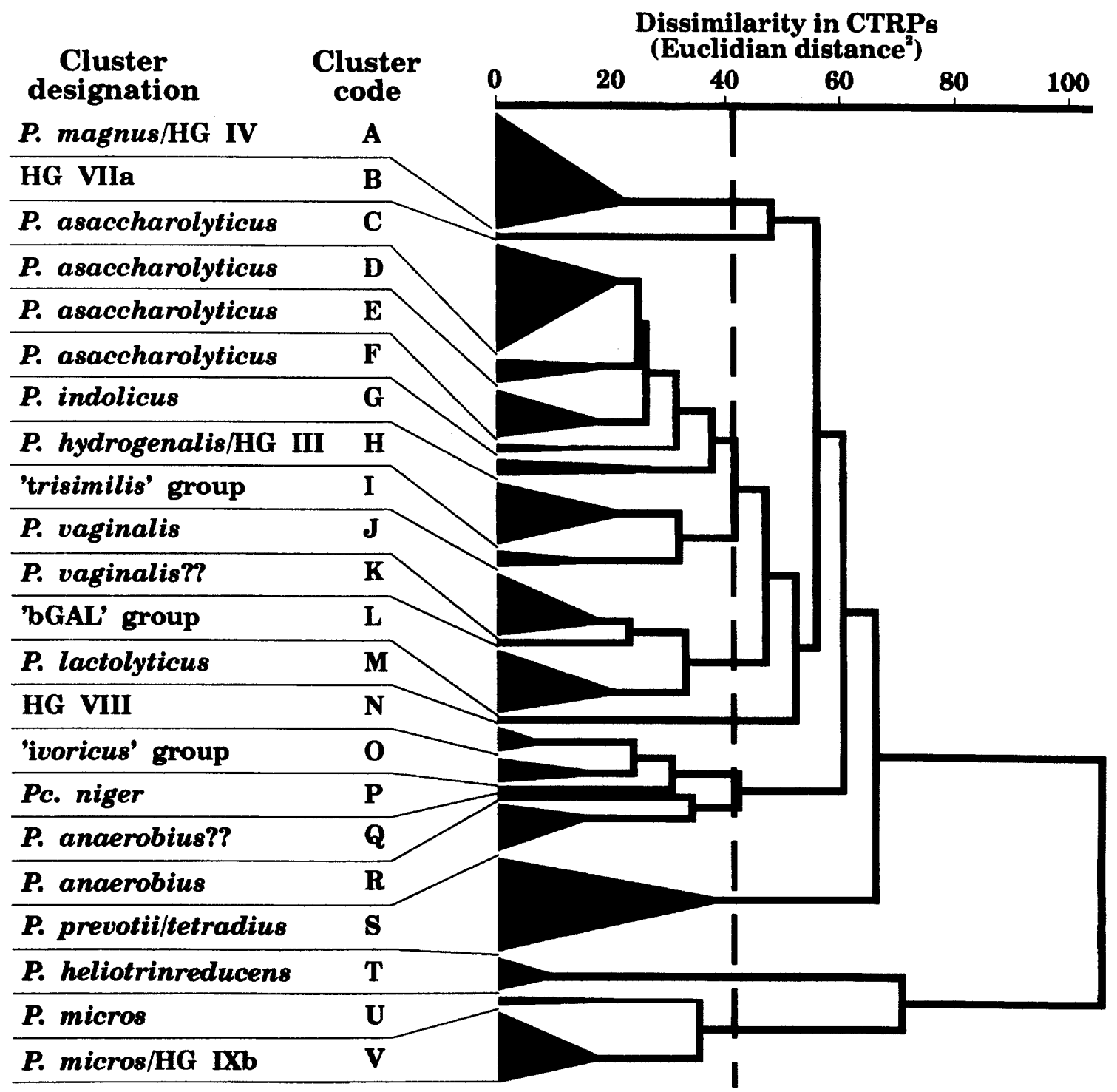

Fig. 1. Dendrogram representing GPAC classification from CTRP data. Hare Group is abbreviated to HG.

Much of the dendrogram structure was readily interpreted. Several groups formed exclusive clusters in both data sets: $P$. magnus with Hare group IV; $P$. hydrogenalis with Hare group III; "trisimilis" group strains; Hare group VIII; and $P$. heliotrinreducens. The type strain of $P$. heliotrinreducens (NCTC 11029) failed to grow for PMS analysis but was typical in CTRPs.

For other groups, the clustering patterns were more complex, but an underlying pattern of equivalence between CTRP and PMS clusters remained evident. Thirteen strains described as the "prevotii/tetradius group" formed a complex in a diverse CTRP cluster and in three PMS groups. Within-strain reproducibility of PEPs for this group was poor and is reflected in their diffuse clustering (fig. 1). The type strain of $P$. indolicus and two clinical strains formed a single diffuse CTRP cluster but two distinct PMS groups. Twelve strains representing $P$. micros formed two CTRP clusters and three PMS groups; the strain representative of Hare group IXb was a typical member.

The type strain of $P$. vaginalis clustered with four
"ADH" group strains in both data sets. Four further clinical strains were typical in CTRPs but were clearly distinct in PMS, and the single indole-positive clinical isolate was atypical in CTRPs and PMS (cluster K; group 10). Clinical strains representing the previously designated "bGAL" group ${ }^{14}$ formed CTRP cluster L and PMS groups 5, 6 and 10. The type strain of $P$. lactolyticus formed a single member cluster (M), but clustered in PMS group 10 with the aberrant $P$. vaginalis strain and two isolates of the "bGAL" group.

However, strains representing $P$. asaccharolyticus formed four groups in CTRPs and in PMS. The type strain, NCTC 11461, was an outlier of CTRP cluster C and grossly atypical in PMS (group 21). Eleven strains of CTRP cluster $\mathrm{C}$ and one member of cluster $\mathrm{F}$ formed a compositionally homogeneous group (PMS group 1); these showed close similarity in colonial and microscopic morphology and were previously designated " $P$. asaccharolyticus $A "{ }^{8,14}$ Similarly, PMS group 18 comprised the nine clinical strains representing the group previously designated " $P$. asaccharolyticus B", ${ }^{14}$ but these were scattered in CTRP clusters C, D, E and F. In PMS and in colonial 


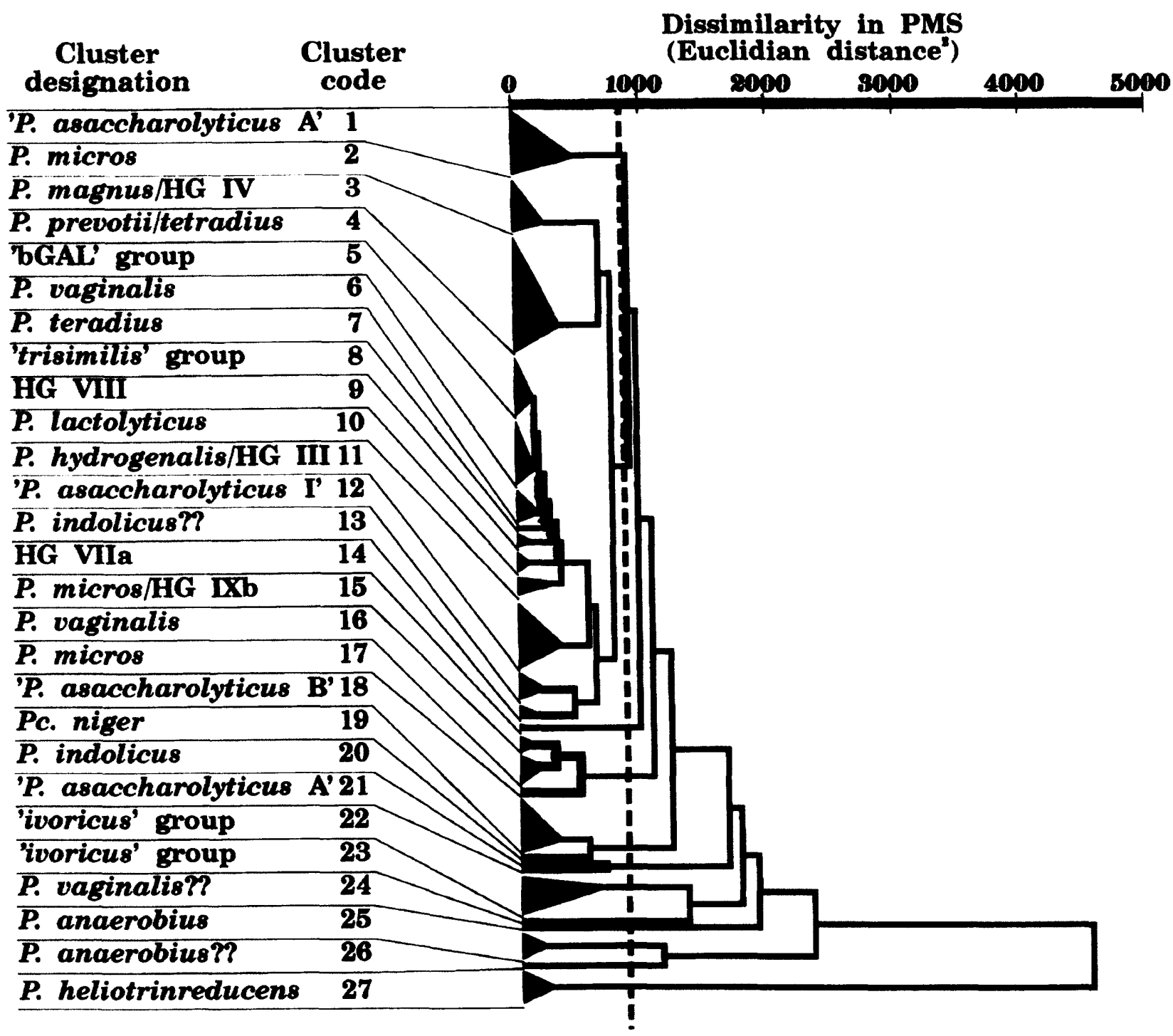

Fig. 2. Dendrogram representing GPAC classification from PMS data. Hare Group is abbreviated to HG.

and microscopic morphology, these strains were clearly homogenous and distinct from " $P$. asaccharolyticus A". Four clinical strains resembling " $P$. asaccharolyticus $\mathrm{A}$ " in morphology formed PMS group 12. These were members of CTRP cluster $E$ and were termed " $P$. asaccharolyticus I".

The clear separation of the groups " $P$. asaccharolyticus A" and "P. asaccharolyticus I" in PMS conflicted with their similarities in colonial and microscopic morphology. The sole consistent difference between these groups in CTRPs was in their ability to produce detectable quantities of indole. A pyrolysis spectrum of pure indole showed an intense mass representing intact indole at $\mathrm{m}: \mathrm{z} 117$ and two minor pyrolysis products at $m: z 90$ and 63 . Removal of these masses from the spectrum data and re-analysis gave a further dendrogram in which the " $P$. asaccharolyticus $A$ " and "P. asaccharolyticus I" groups fused. All other PMS groups remained intact.

The type strain of $P$. anaerobius and six clinical strains formed CTRP cluster R; the majority of these formed PMS group 25. However, two clinical strains clustered with the "ivoricus" group strains in PMS group 22. These strains, like those in the "ivoricus" group, did not produce iso-caproic acid, but were otherwise closely similar to $P$. anaerobius in CTRPs. A pyrolysis spectrum of iso-caproic acid revealed four major products but removal of these from the spectrum data did not change cluster membership. One atypical clinical strain formed CTRP cluster Q and PMS group 26. The four clinical strains of the "ivoricus" group formed CTRP cluster O and PMS groups 22 and 23.

Of the single member groups (table II), NCTC 9808 and NCTC 11805 were always distinct. NCTC 9801, NCTC 9811, DSM 7455 and DSM 3244 clustered with other strains, but were invariably outliers, and the clusters with which they linked varied with the similarity coefficient used. Each of these strains probably represents a distinct group.

\section{Identification analyses}

Blind identification (table III) from PMS data yielded results that agreed with cluster membership for $>95 \%$ of isolates. The rate was similar for most groups tested and provides confirmation that the major clusters were cohesive in composition as re- 
Table III. Results of blind identification trial

\begin{tabular}{|c|c|c|c|}
\hline \multirow[t]{2}{*}{$\begin{array}{l}\text { Group } \\
\text { designation }\end{array}$} & \multirow{2}{*}{$\begin{array}{l}\text { Total } \\
\text { number of } \\
\text { strains }\end{array}$} & \multicolumn{2}{|c|}{$\begin{array}{l}\text { Agreement between joint } \\
\text { classification results } \\
\text { and identification in } \dagger\end{array}$} \\
\hline & & PMS & CTRPs \\
\hline P. magnus & 15 & 100 & 100 \\
\hline$" P$. asaccharolyticus $\mathrm{A}+\mathrm{I} "$ & 12 & 100 & 83 \\
\hline$" P$. asaccharolyticus B" & 9 & 100 & 33 \\
\hline P. hydrogenalis & 9 & 100 & 67 \\
\hline$P$. vaginalis & 9 & $89^{*}$ & 89 \\
\hline “bGAL” group & 9 & $78^{*}$ & 78 \\
\hline$P$. anaerobius & 8 & 75 & 75 \\
\hline P. prevotii/tetradius & 13 & $100^{*}$ & 69 \\
\hline P. micros & 12 & 100 & 100 \\
\hline P. heliotrinreducens & 5 & 100 & 100 \\
\hline
\end{tabular}

* One strain of the group yielded equivocal results from the quadruplicate spectra.

$\dagger$ Figures indicate the percentage of strains within each joint PMS and CTRP classification group that were identified to that group on the basis of blind identification from PMS data, or from CTRP data alone.

flected in PMS. For identification from CTRP data, agreement was lower, at $80 \%$, and poor $(<70 \%)$ for several groups, particularly strains of $P$. prevotii/ tetradius and " $P$. asaccharolyticus B".

\section{Discussion}

Most GPAC use proteins and amino acids as their major energy source $\mathbf{2 , 9 , 1 0}$ and are not amenable to identification methods based on carbohydrate fermentation reactions. ${ }^{4,10,11}$ The introduction of PEPs $^{9,12-14}$ has greatly increased the range of appropriate tests. The current study validates their use in identification and confirms the taxonomic anomalies found in an earlier PEP-based study. ${ }^{14}$

A disturbing feature of the study was that type strains frequently appeared as outliers, atypical in CTRPs, PMS or both. Examples include P. asaccharolyticus NCTC $11461, P$. prevotii NCTC $11806, P$. tetradius ATCC 35098, P. micros NCTC 11808 and $P$. indolicus NCTC 11088. It is possible that the cumulative effects of storage, subculture on laboratory media and exposure to oxygen may have selected atypical clones. These strains are highlighted to warn other workers that they may not be representative of fresh clinical isolates.

GPAC have been divided into three groups on the basis of the highest mol. wt acid detectable in their VFA profiles. ${ }^{14}$ This arbitrary division yields an acetate group comprising $P$. magnus, $P$. micros and $P$. heliotrinreducens, a butyrate group currently containing eight species, and a long-chain VFA group currently containing $P$. anaerobius and $P c$. niger.

In the acetate group, there was complete agreement between CTRP and PMS classifications. Earlier identification schemes ${ }^{4,10,11,23}$ distinguished $P$. magnus and $P$. micros solely by cell size and, in some schemes, production of alkaline phosphatase. ${ }^{4,10}$ These species were clearly distinct and homogeneous in CTRPs and
PMS, and are reliably discriminated in PEPs. ${ }^{14}$ Both species are important pathogens, ${ }^{8,24,25}$ but difficulties in earlier identification schemes have undoubtedly held back studies of their clinical importance. Strains of $P$. heliotrinreducens were tightly homogeneous and markedly distinct from all other GPAC, in agreement with $16 \mathrm{~S}$ rRNA sequence analysis. ${ }^{15}$ They are biochemically similar to some species currently classified in the genus Eubacterium. $P$. heliotrinreducens is readily differentiated from $P$. micros by PEPs and colonial morphology ${ }^{14}$ and has been isolated from polymicrobial abscesses. ${ }^{26}$

The taxonomy of the butyrate group, which contains several undescribed taxa, ${ }^{14,15}$ is less satisfactory. There is strong evidence that $P$. asaccharolyticus, the species of greatest clinical importance, ${ }^{6-8}$ is heterogeneous. ${ }^{2,14,16,17,27}$ Earlier work on the strains examined here distinguished two groups termed " $P$. asaccharolyticus $\mathrm{A}$ " and " $P$. asaccharolyticus B", mainly on the basis of colonial and cellular morphology..$^{14}$ PMS supported this separation but PEPs failed to differentiate the groups reliably. This is an area where improvements in characterisation are still required.

Standard reference manuals ${ }^{4,10,23}$ cite this species as forming indole, but eight strains in the $P$. asaccharolyticus complex failed to produce indole in detectable amounts. Mass 117, the indole mass, has shown poor within-strain reproducibility in PMS studies, probably because small variations in sample film thickness, storage and processing of foils have large effects on loss of this volatile compound. Its inclusion in the initial analysis of this survey led to anomalous clustering of the indole-negative strains of " $P$. asaccharolyticus A". Indole is a metabolite, not a cell constituent, and would best be excluded in PMS taxonomic surveys where the intent is to cluster on the basis of cell composition.

Hare group III and $P$. hydrogenalis formed a tight exclusive cluster in CTRPs and PMS, confirming that 
they are synonymous. $P$. hydrogenalis was distinguished from the $P$. asaccharolyticus complex by its fermentation of mannose and lack of proteolytic activity in the ATB $32 \mathrm{~A}$ tests; all strains formed indole. The three strains in the "trisimilis" group formed a tight, exclusive cluster in both data sets. Their PEPs were similar to those of $P$. hydrogenalis, with formation of indole and fermentation of mannose, but they were differentiated by their production of pyroglutamyl arylamidase. Thirteen strains, including the type strains of $P$. prevotii and $P$. tetradius, formed a discrete group marked by their strong saccharolytic activity and production of urease; this complex probably constitutes a distinct genus.

Most "ADH " ${ }^{14}$ strains clustered with $P$. vaginalis in both data sets, but there was some limited overlap in PMS with the "bGAL" group described in an earlier PEP-based study. ${ }^{14}$ These groups are of considerable importance, representing $11 \%$ of clinical strains in a recent survey, compared to $3 \%$ for $P$. hydrogenalis and "trisimilis" strains and $2 \%$ for $P$. prevotii/tetradius strains. ${ }^{8} P$. vaginalis and "bGAL" strains probably account for a large proportion of the clinical isolates previously identified as $P$. prevotii. ${ }^{1,2,5-7}$ Further studies on the classification of these organisms are needed.

GPAC that produce VFAs beyond butyrate are less varied. "Ivoricus" strains were clearly distinguished from $P$. anaerobius in CTRPs, PEPs and morphology, but in PMS there was some overlap that correlated with VFA profiles. Strains of Hare group VIII and $P c$. niger produced $n$-caproate, but were clearly distinct in PEPs, CTRPs and PMS. Hare group VIII strains formed a discrete and exclusive group in both data sets and clearly represent another undescribed species.

$P c$. niger is placed in a separate genus because its $\mathrm{G}+\mathrm{C}$ ratio $(51 \mathrm{~mol} \%)^{10}$ is clearly different from species at present in the genus Peptostreptococcus $(\mathrm{G}+\mathrm{C} 28-37 \mathrm{~mol} \%)^{10}$ Its position in the dendrograms indicates that the genus Peptostreptococcus should be split into about 10 different genera, in accordance with the 16s rRNA sequence data of Li $e t$ $a l .^{15} \mathrm{We}$ suggest that the following groups or species deserve distinct generic epithets at minimum. $P$. prevotii/tetradius, $P$. vaginalis, $P$. hydrogenalis, $P$. lactolyticus, Hare group VIII and the "bGAL" and "trisimilis" groups formed a clear supercluster in PMS. P. anaerobius and the "ivoricus" group were clearly distinct from other groups in biochemistry and PMS. P. micros and P. magnus were distinct from one another and from other species. Finally, $P$. heliotrinreducens was so grossly dissimilar from the Peptococcus/Peptostreptococcus supercluster that it would be better assigned to another group.
This study shows that numerous taxa, particularly in the butyrate group, await description; many clinical strains yield distinctive PEPs that do not fit with any recognised species. The use of PEPs is clearly of taxonomic value, as shown by the informal description of the "ADH" group and Hare group III ${ }^{14,28}$ before their formal recognition as $P$. vaginalis $^{29}$ and $P$. hydrogenalis ${ }^{30}$ respectively.

The study also provides further evidence that the indole test is of limited value in the division of GPAC. Most standard texts consider indole production to be a key test for the identification of butyrate group species, often splitting them into indole-positive and indole-negative groups, ${ }^{4,10}$ but several lines of evidence indicate that it is of little value. ${ }^{14,16,27}$ No single biochemical test is likely to be useful for the large number of species in this group; identification should be based on a broad range of tests appropriate to the physiology of these organisms.

In conclusion, the results of a previous study based on PEPs $^{14}$ were confirmed, validating their use in characterising GPAC. PEPs provide a simple reliable and discriminatory method for identifying GPAC that is suitable for use in routine laboratories. However, the deficiencies of the current classification need to be addressed. The following were clearly synonymous: Hare group III $=P$. hydrogenalis $;$ Hare group IV $=P$. magnus; Hare group IXb $=P$. micros, and the "ADH group" = $P$. vaginalis. Five unrecognised groups were found: Hare group VIII, and the groups termed " $P$. asaccharolyticus B"; "trisimilis", "ivoricus" and "bGAL". The level of heterogeneity in CTRPs and PMS strongly suggests that GPAC encompass more genera than the currently recognised Peptococcus and Peptostreptococcus.

In the past, inadequate taxonomy yielded misleading descriptions of the mean pathogenicity and biochemistry of GPAC "species" that were in fact mixed groups. This resulted in difficulties in identification, and a poor predictive value of identification that discouraged clinical and laboratory studies. This invidious cycle has been broken; nucleic acid techniques are resolving the taxonomic problems $s^{15,29,30}$ and PEPs provide a simple method for identification in clinical surveys. ${ }^{8}$ Together, these developments now allow routine laboratory identification of GPAC to groups with defined and distinct clinical properties, giving predictive value to the identification of GPAC.

We are grateful to the staff of the laboratories at St Bartholomew's Hospital, London (particularly I. Mitchelmore), Southmead Hospital, Bristol, and the Anaerobe Reference Unit, Cardiff for their assistance, and Val Hall of the Anaerobe Reference Unit, Cardiff for the suggestion that $P$. heliotrinreducens might be similar to the eubacterium group. This work was supported by grants from the Showering Fund and the Sir Jules Thorn Trust.

\section{References}

1. Neut C, Lesieur V, Romond C et al. Analysis of gram-positive anaerobic cocci in oral, fecal and vaginal flora. Eur J Clin Microbiol $1985 ; 4: 435-437$.
2. Holdeman Moore LV, Johnson JL, Moore WEC. Genus Peptococcus; Genus Peptostreptococcus. In: Sneath PHA (eds. Mair NS, Sharpe ME, Holt JG) Bergey's Manual of systematic bacteriology, vol. 2. Baltimore, Williams and Wilkins. 1986: 1082-1083; 1083-1092. 
3. Bartlett JG. Anaerobic cocci. In: Mandell GL, Douglas RG, Bennett JE (eds) Principles and practice of infectious diseases, 3rd edn. New York, Churchill Livingstone. 1990: $1867-1869$.

4. Summanen P, Baron EJ, Citron DM et al. Wadsworth anaerobic bacteriology manual, 5th edn. Los Angeles, Star Publishing Co. 1993.

5. Wren MWD, Baldwin AWF, Eldon CP, Sanderson PJ. The anaerobic culture of clinical specimens: a 14-month study. J Med Microbiol 1977; 10: 49-61.

6. Rosenblatt JE. Anaerobic cocci. In: Lennette EH, Balows A Hausler WJ, Shadomy HJ (eds) Manual of clinical microbiology, 4th edn. Washington, American Society for Microbiology. 1985: 445-449.

7. Brook I. Recovery of anaerobic bacteria from clinical specimens in 12 years at two military hospitals. J Clin Microbiol 1988; 26: 1181-1188.

8. Murdoch DA, Mitchelmore IJ, Tabaqchali S. The clinical importance of gram-positive anaerobic cocci isolated at $\mathrm{St}$ Bartholomew's Hospital, London, in 1987. J Med Microbiol 1994; 41 : 36-44.

9. Ezaki T, Yabuuchi E. Oligopeptidase activity of Gram-positive anaerobic cocci used for rapid identification. J Gen Appl Microbiol 1985; 31: 255-265.

10. Ezaki T, Oyaizu H, Yabuuchi E. The anaerobic gram-positive cocci. In: Balows A et al. (eds) The prokaryotes, 2nd edn. Berlin, Springer-Verlag. 1991: 1879-1892.

11. Hillier S, Moncla BJ. Anaerobic gram-positive nonspore forming bacilli and cocci. In: Balows A, Hausler WJ, Herrmann KL, Isenberg HD, Shadomy HJ (eds) Manual of clinical microbiology, 5th edn. Washington, American Society for Microbiology. 1991: 522-537.

12. Stenson MJ, Lee DT, Rosenblatt JE, Contezac JM. Evaluation of the AnIdent system for the identification of anaerobic bacteria. Diagn Microbiol Infect Dis 1986; 5: 9-15.

13. Murdoch DA, Mitchelmore IJ, Tabaqchali S. Identification of gram-positive anaerobic cocci by use of systems for detecting pre-formed enzymes. J Med Microbiol 1988; 25: 289-293.

14. Murdoch DA, Mitchelmore IJ. The laboratory identification of gram-positive anaerobic cocci. J Med Microbiol 1991; 34: 295-308.

15. Li N, Hashimoto Y, Ezaki T. Determination of $16 \mathrm{~S}$ ribosomal RNA sequences of all members of the genus Peptostreptococcus and their phylogenetic position. FEMS Microbiol Lett 1994; 116: 1-6.

16. Harpold DJ, Wasilauskas BL. Rapid identification of obligately anaerobic gram-positive cocci using high-performance liquid chromatography. J Clin Microbiol 1987; 25: 996-1001.

17. Ng L-K, Dillon J-AR. Molecular fingerprinting of isolates of the genus Peptostreptococcus using rRNA genes from Escherichia coli and P. anaerobius. J Gen Microbiol 1991; 137: 1323-1331.

18. Magee J. Whole-organism fingerprinting. In: Goodfellow $M$, O'Donnell AG (eds) Handbook of new bacterial systematics. London, Academic Press. 1993: 383-427.

19. Hindmarch JM, Magee JT, Hadfield MA, Duerden BI. A pyrolysis-mass spectrometry study of Corynebacterium spp. J Med Microbiol 1990; 31 : 137-149.

20. Magee JT, Hindmarch JM, Bennett KW, Duerden BI, Aries RE. A pyrolysis mass spectrometry study of fusobacteria. $J$ Med Microbiol 1989; 28: 227-236.

21. Winstanley TG, Magee JT, Limb DI. A numerical taxonomic study of the "Streptococcus milleri" group based upon conventional phenotypic tests and pyrolysis mass spectrometry. J Med Microbiol 1992; 36: 149-155.

22. Wishart D. Clustan user's manual, 4th edn. Computing Laboratory, University of St Andrews. 1987.

23. Holdeman LV, Cato EP, Moore WEC. Anaerobe laboratory manual, 4th edn. Blacksburg, Virginia Polytechnic Institute and State University. 1977.

24. Bourgault A-M, Rosenblatt JE, Fitzgerald RH. Peptococcus magnus: a significant human pathogen. Ann Int Med 1980; 93: $244-248$

25. Murdoch DA, Mitchelmore IJ, Tabaqchali S. Peptostreptococcus micros in polymicrobial abscesses. Lancet 1988; 1 : 594.

26. Murdoch DA, Mitchelmore IJ. Isolation of Peptostreptococcus heliotrinreducens from human polymicrobial abscesses. Lett Appl Microbiol 1989; 9: 223-225.

27. Taylor EA, Jackman PJH, Phillips I. The differentiation of asaccharolytic anaerobic gram-positive cocci by protein electrophoresis. J Med Microbiol 1991; 34: 339-348.

28. Murdoch DA, Mitchelmore IJ, Nash RA, Hardie JM, Tabaqchali S. Preformed enzyme profiles of reference strains of gram-positive anaerobic cocci. J Med Microbiol $1988 ; 27: 65-70$.

29. Li N, Hashimoto Y, Adnan S, Miura H, Yamamoto H, Ezaki T. Three new species of the genus Peptostreptococcus isolated from humans: Peptostreptococcus vaginalis sp. nov., Peptostreptococcus lacrimalis sp. nov., and Peptostreptococcus lactolyticus sp. nov. Int $J$ Syst Bacteriol $1992 ; 42: 602-605$

30. Ezaki T, Liu S-L, Hashimoto Y, Yabuuchi E. Peptostreptococcus hydrogenalis sp. nov. from human fecal and vaginal flora. Int J Syst Bacteriol 1990; 40: 305-306. 